\title{
Cell kinetics during regeneration in the sponge Halisarca caerulea: how local is the response to tissue damage?
}

Brittany E Alexander, Michelle Achlatis, Ronald Osinga, Harm G van der Geest, Jack P M Cleutjens, Bert Schutte, Jasper M de Goeij

Sponges have a remarkable capacity to rapidly regenerate in response to wound infliction. In addition, sponges rapidly renew their filter systems (choanocytes) to maintain a healthy population of cells. This study describes the cell kinetics of choanocytes in the encrusting reef sponge Halisarca caerulea during early regeneration $(0-8 \mathrm{~h})$ following experimental wound infliction. Subsequently, we investigated the spatial relationship between regeneration and cell proliferation over a six-day period directly adjacent to the wound, 1 $\mathrm{cm}$ and $3 \mathrm{~cm}$ from the wound. Cell proliferation was determined by the incorporation of 5 bromo-2'-deoxyuridine (BrdU). We demonstrate that during early regeneration, the growth fraction of the choanocytes (i.e. the percentage of proliferative cells) adjacent to the wound is reduced $(7.0 \pm 2.5 \%)$ compared to steady-state, undamaged tissue (46.6 \pm 2.6 $\%$ ), while the length of the cell cycle remained short (5.6 $\pm 3.4 \mathrm{~h})$. The percentage of proliferative choanocytes increased over time in all areas and after six days of regeneration choanocyte proliferation rates were comparable to steady-state tissue. Tissue areas farther from the wound had higher rates of choanocyte proliferation than areas closer to the wound indicating that more resources are demanded from tissue in the immediate vicinity of the wound. There was no difference in the number of proliferative mesohyl cells in regenerative sponges compared to steady-states ponges. Our data suggest that the production of collagen-rich wound tissue is a key process in tissue regeneration for $H$. caerulea, and helps to rapidly occupy the bare substratum exposed by the wound. Regeneration and choanocyte renewal are competing and negatively correlated life-history traits, both essential to the survival of sponges. The efficient allocation of limited resources to these life-history traits has enabled the ecological success and diversification of sponges. 
2 Authors: Brittany E. Alexander ${ }^{1,2^{*}}$, Michelle Achlatis ${ }^{1}$, Ronald Osinga ${ }^{2}$, Harm G. van der Geest ${ }^{1}$,

3 Jack P. M. Cleutjens ${ }^{3}$, Bert Schutte ${ }^{4}$, Jasper M. de Goeij ${ }^{1,2}$

4

$5 \quad{ }^{1}$ Department of Aquatic Ecology and Ecotoxicology, Institute for Biodiversity and Ecosystem

6 Dynamics, University of Amsterdam, Amsterdam, The Netherlands.

$7 \quad 2$ Porifarma B.V., Ede, The Netherlands.

$8 \quad{ }^{3}$ Department of Pathology, Cardiovascular Research Institute Maastricht, Maastricht, The Netherlands.

$9 \quad{ }^{4}$ Department of Molecular Cell Biology, Research Institute Growth and Development, Maastricht

10 University, Maastricht, The Netherlands.

11

12 * Corresponding author: Brittany Alexander

13 Address: Department of Aquatic Ecology and Ecotoxicology,

14 Institute for Biodiversity and Ecosystem Dynamics,

15 University of Amsterdam, Amsterdam, The Netherlands.

16 Email: B.E.Alexander@uva.nl or britt.e.alexander@gmail.com

17 Telephone: $(+31) 657521195$

18

19

20

21

22

23

24 
Introduction

Sponges (Porifera) are highly successful organisms. More than 8,500 species have been described to date (van Soest et al., 2015) and they are among the oldest extant metazoans on Earth (Müller 1998; Philippe et al., 2009; Antcliffe, Callow \& Brasier 2014). Sponges often dominate the benthic cover of diverse marine and freshwater ecosystems from tropical to polar regions (e.g. Gili \& Coma 1998; Bell \& Barnes 2000; McClintock et al., 2005). Their high cellular (Müller 2006; Funayama 2013) and morphological (Gaino \& Burlando 1990) plasticity allows them to constantly adjust the shape and size of their tissues and adapt to variations in environmental conditions (e.g. Gaino, Manconi \& Pronzato 1995; Bell, Barnes \& Turner 2002). The ecological success of sponges is partially a result of their rapid regeneration capacity enabling them to recover from damage caused by predation (Ayling 1983), storm (Wulff 2006a; Wulff 2006b; Wulff 2010) and environmental stress (Luter, Whalen \& Webster 2012). Additionally, sponges play and important ecological role in the recycling of energy and nutrients within their ecosystems by rapidly renewing their cells through proliferation and shedding (De Goeij et al., 2009; De Goeij et al., 2013; Alexander et al., 2014). Sponges pump vast amounts of water through their bodies and their choanocytes (filter cells) are constantly renewed, presumably to prevent damage by exposure to physical, chemical and biological stress from their environment (De Goeij et al., 2009). The choanocytes of the tropical reef sponge Halisarca caerulea (Porifera: Demospongiae) proliferate rapidly under steady-state, non-growing conditions, with a cell-cycle duration of approximately 6 h (De Goeij et al., 2009). Rapid cell proliferation is balanced with massive amounts of cell shedding into the lumen of the excurrent canals in order to maintain tissue homeostasis in the choanocyte compartment. However, it is unknown how cell renewal in sponges changes in response to external cues. In highly proliferative tissues of other organisms, cell proliferation is often altered in response to starvation, tissue damage and infection. For 
49 example, cell proliferation becomes reduced in response to starvation in the mammalian

50 gastrointestinal tract (Aldewachi et al., 1975; Chaudhary et al., 2000) and the Drosophila melanogaster

51 midgut (McLeod et al., 2010), and increases as a result of tissue damage and infection in both systems

52 (gastrointestinal tract: Gilbert et al., 2015; Boshuizen et al., 2003, D. melanogaster midgut: Buchon et

53 al., 2009; Jiang et al., 2011).

54 Sponges are considered to exhibit the highest regenerative capacity among metazoans displaying

55 up to 2,900 times their normal growth rate following injury (Ayling 1983). Regeneration is an

56 energetically demanding process, demonstrated by an increased metabolic rate after tissue damage in

57 the sponge Haliclona oculata (Koopmans et al., 2011). Energy availability is limited and must be

58 distributed between several potentially competing life-history traits such as maintenance, repair,

59 growth and reproduction (Zera \& Harshman 2001). Energetic resources are often redirected into

60 regenerative processes after tissue damage, potentially limiting energy available for other life history

61 processes (Henry \& Hart 2005). Somatic growth, sexual reproduction and chemical defense

62 mechanisms can become compromised during tissue regeneration in sponges (Henry \& Hart 2005;

63 Walters \& Pawlik 2005; Leong \& Pawlik 2010). The relationship between regeneration and rapid cell

64 turnover in sponges, both essential life-history traits, is unknown.

65

66

67

68

69

70

71
Sponges are modular organisms consisting of multiple repeated units, known as aquiferous modules (Ereskovskii 2003), which may respond differently to tissue damage depending on their distance from the wound. An aquiferous module is a volume of sponge that is associated with a single osculum and supplied by an anatomically-defined aquiferous system of canals and choanocyte chambers (Fry 1970; Fry 1979). The degree of integration between aquiferous modules depends on the number and distribution pattern of oscula, with mono-oscular sponges being the most integrated and multi-oscular sponges being the least integrated (Ereskovskii 2003). Therefore, in thin, encrusting, 
72 multi-oscular sponges such as H. caerulea, tissue damage may have a larger impact on the physiology

73 of aquiferous modules closer to the site of injury.

74 This study aims to gain insight into the potential trade-off between regeneration and cell

75 proliferation in our model species, $H$. caerulea. We investigate the impact of tissue damage on

76 choanocyte cell kinetics during initial stages of regeneration and choanocyte proliferation rates at later

77 stages of regeneration along a spatial gradient from the wound. Additionally, we examine the role of

78 mesohyl cell proliferation and collagen production during regeneration.

80 Materials and Methods

81 Sponge collection

82

83

84

85

86

87

88

89

90

91

92

93

94

95

Specimens of $H$. caerulea were collected at water depths between 15 and $30 \mathrm{~m}$ by SCUBA diving on the reefs of the Caribbean island of Curaçao $\left(12^{\circ} 12^{\prime} \mathrm{N}, 68^{\circ} 56^{\prime} \mathrm{W}\right)$ between February and April 2013. Fieldwork was performed under the research permit (\#2012/48584) issued by the Curaçaoan Ministry of Health, Environment and Nature (GMN) to the CARMABI foundation. Pieces of sponge were chiseled from the reef framework and the attached coral rock substrate was cleared of other organisms. All sponges were trimmed to a size of approximately $25 \mathrm{~cm}^{2}$. Specimens were kept in 100 $\mathrm{L}$ aquaria filled with unfiltered running seawater pumped from $10 \mathrm{~m}$ water depth from the reef slope, with a flow rate of $3 \mathrm{~L} \mathrm{~min}^{-1}$. Aquarium water was at ambient temperature $\left(26-27^{\circ} \mathrm{C}\right)$ and under natural light cycles. Aquaria were shaded with semi-transparent black plastic sheets to imitate cryptic light conditions. Sponges were allowed to acclimatize for a minimum of two weeks prior to experimentation. The mean $( \pm \mathrm{SE})$ distance between oscula was measured in ImageJ from photographs of the sponges in order to estimate if tissue samples were likely to be part of the same aquiferous module.

Induction of tissue damage, BrdU-labeling, tissue fixation and embedding 
Tissue damage was induced by removing a small piece of tissue $\left(\sim 1 \mathrm{~cm}^{2}\right)$ from the center of the sponge using a scalpel, and exposing the bare substrate (Fig. 1A). Wounded sponges were placed in individual incubation chambers $(3 \mathrm{~L})$ containing magnetic stirring devices. The incubation chambers were kept in the aquaria to maintain ambient seawater temperature (De Goeij et al., 2009; Alexander et al., 2014). In order to determine cell cycle parameters (e.g. length of the cell cycle, growth fraction) of choanocytes directly after wound infliction (here on referred to as 'early regenerative tissue'), sponges were continuously labeled with $50 \mu \mathrm{mol} \mathrm{L}^{-1}$ 5-bromo-2'-deoxyuridine (BrdU, Sigma) directly after wounding for $t=0,0.5,1.5,2,6$, and $8 \mathrm{~h}$ ( $n=3$ for each time point). After BrdU-labeling, a tissue sample $\left(\sim 0.5 \mathrm{~cm}^{2}\right)$ directly adjacent to the wound was removed from each sponge (Fig 1A).

To determine cell proliferation during regeneration, sponges were left to regenerate for $t=0,1$, 2 and 6 days after wound infliction ( $n=3$ for each time point), then were continuously labeled with BrdU for $6 \mathrm{~h}$. After BrdU-labeling, three tissue samples $\left(\sim 0.5 \mathrm{~cm}^{2}\right)$ were removed from each sponge; (1) directly adjacent to the wound, (2) approximately $1 \mathrm{~cm}$ from the wound and (3) approximately $3 \mathrm{~cm}$ from the wound (Fig. 1A). Tissue samples adjacent to the wound were marked with an arrow shape so the orientation of the tissue could be recognized and histological sections could be made which included the wound area (Fig 1A). Tissue was fixed in 4\% paraformaldehyde in phosphate-buffered saline (PFA/PBS; $\mathrm{pH}$ 7.4-7.6, $4 \mathrm{~h}$ at $4^{\circ} \mathrm{C}$ ), rinsed in PBS, dehydrated through a graded series of ethanol and stored in $70 \%$ ethanol at $4^{\circ} \mathrm{C}$ until further processing. All tissue samples were embedded in butylmethyl-methacrylate (BMM) within one week.

\section{BrdU-immunohistochemistry}


121 acetone and endogenous peroxidase activity was blocked by incubating slides in methanol containing

$1220.3 \% \mathrm{H}_{2} \mathrm{O}_{2}(20 \mathrm{~min})$. Slides were washed in tris-buffered saline (TBS) and incubated in citric acid

$123\left(0.2 \%\right.$; $\mathrm{pH} 6.0,30 \mathrm{~min}$ at $\left.85^{\circ} \mathrm{C}\right)$. After subsequent washing in TBS, DNA was denatured in $\mathrm{HCl}(2 \mathrm{~mol}$ $124 \mathrm{~L}^{-1}, 30 \mathrm{~min}$ at $37^{\circ} \mathrm{C}$ ), $\mathrm{pH}$-neutralized in sodium borate buffer (pH 8.5), and washed with TBS. Slides

125 were incubated with mouse anti-BrdU monoclonal antibody (Nordic-MUbio MUB0200S, 1:50 in TBS 126 with $1 \%$ BSA, 0.1\% Tween 20, 60 min) then washed in TBS. Primary antibody was detected using an 127 avidin-biotin enzyme complex (Vectastain Elite ABC Kit, Vector laboratories). Slides were incubated 128 with biotinylated rabbit anti-mouse antibody (in TBS with 1\% BSA, 0.1\% Tween 20, 30 min), washed 129 in TBS and then incubated in avidin-biotin-peroxidase complex (in TBS with 1\% BSA, 0.1\% Tween $13020,30 \mathrm{~min}$ ). Peroxidase activity was visualized with DAB (DAKO; 5-10 min; positive cells have 131 brown-stained nuclei). Sections were washed in distilled water then counterstained in hematoxylin to 132 visualize BrdU-negative nuclei (stained dark blue), dehydrated through a graded series of ethanol and 133 mounted in Entellan (Merck). BrdU-labeled mouse intestinal tissue was used as a positive control and 134 immunohistochemistry without primary antibody (on both mouse and sponge tissue) served as a 135 negative control (Alexander et al., 2014).

\section{Analysis of choanocyte cell kinetics}

All slides were examined under a light microscope (Olympus BH-2) and photographs were

139 taken using an Olympus DP70 camera. To investigate the cell kinetics of the choanocyte population

140 directly next to the wound (the wound tissue contained no choanocyte chambers, Fig 2A) in early

141 regenerative tissue, percentages of BrdU-positive choanocytes were determined at each time point: $t=$ $1420,0.5,1.5,2,6,8 \mathrm{~h}$. Three histological sections were made from each tissue sample, each 
143 approximately $100 \mu \mathrm{m}$ apart (Fig 1A). From each section at least 400 choanocytes were counted 144 making a total of at least 1200 (3 sections x 400 cells) choanocytes counted per sponge. The 'one 145 population model' (Nowakowski et al., 1989; De Goeij et al., 2009) was used to estimate the growth 146 fraction (GF; percentage of choanocytes involved in proliferation), duration of the cell cycle $\left(\mathrm{T}_{c}\right)$, 147 labeling index (LI; percentage of choanocytes in S-phase), and the duration of the S-phase $\left(\mathrm{T}_{s}\right)$ for 148 choanocytes in early regenerative tissue. Parameters (mean $\pm 95 \%$ confident intervals) were estimated 149 from the model according to an iterated least squares fit of the data using the following specified initial 150 conditions:

151

152

153

154

155

156

157

158

159

160

161

162

163

164

165

166

Data on the cell kinetics of the choanocyte population directly adjacent to the wound in early regenerative tissue were compared to choanocyte kinetics of steady-state sponges measured by De Goeij and colleagues in 2009, as this is the only study describing detailed cell cycle parameters in $H$. caerulea.

\section{Analysis of cell proliferation during regeneration ( $6 \mathrm{~h}-6$ days)}

In order to determine changes in cell proliferation over time, the percentages of BrdU-positive choanocytes and mesohyl cells were determined per time point: $t=0.25,1,2$, and 6 days. Choanocytes were identified as all cells arranged in choanocyte chambers and mesohyl cells were identified as all cells located between the choanocyte chambers and the pinacoderm. From each sponge, histological 
167 168 169 170 171 172 173 174 175 176 177 178 179 180 181 182 183 184 185 186 187 188 189 190

sections were analyzed from tissue samples taken directly adjacent to the wound, $1 \mathrm{~cm}$ from the wound, and $3 \mathrm{~cm}$ from the wound (Fig 1A). Three histological sections were made from each sponge tissue sample, each approximately $100 \mu \mathrm{m}$ apart (Fig 1A). At least 400 choanocytes and 400 mesohyl cells were counted from each histological section making a total of at least 1200 cells ( 3 sections x 400 cells) of each cell population counted per sponge in each area. Means $\pm \mathrm{SE}$ are reported. Measuring percentages of BrdU-positive choanocytes after labeling for $6 \mathrm{~h}$ enables the rate of cell proliferation to be estimated, providing that the length of the cell cycle remains close to $6 \mathrm{~h}$ (Alexander et al., 2014). Cell proliferation during regeneration (6 h - 6 days) was compared to cell proliferation from steadystate sponges kept in the same aquaria during the same experimental fieldwork period as sponges in the current study (Alexander et al., 2014).

\section{Picrosirius red staining of collagen in regenerative tissue}

Collagen content was analyzed in histological sections of sponge tissue directly adjacent to the site of the wound (Fig 1A). BMM was removed with acetone and sections were rehydrated to distilled water, and then incubated in $0.2 \%$ phosphomolybdic acid (PMA) in water (5 min). Sections where incubated in $0.1 \%$ picrosirius red in saturated picric acid $(90 \mathrm{~min})$ followed by $0.01 \mathrm{~mol} \mathrm{~L}^{-1} \mathrm{HCl}(2$ min). Sections were dehydrated in ethanol then mounted in Entellan (Merk). Slides were viewed using a cross polarization filter in order to view thin collagen fibres (green) and thick collagen fibres (orange) (Junqueira et al., 1982). Photographs were taken of the regenerative wound tissue, and areas of tissue away from the wound (within $0.5 \mathrm{~cm}$ ) (Fig 2C, Fig 2D).

\section{Statistical analysis}

Differences in choanocyte proliferation rates over time during regeneration were analyzed at each area (directly adjacent to, $1 \mathrm{~cm}$ and $3 \mathrm{~cm}$ from the wound) using a linear model with time as a 
191 factor. Differences in choanocyte proliferation between each area were analyzed using a mixed linear 192 model with the individual sponge as a random factor (to take into account the nested effect of area 193 within each individual sponge). The choanocyte proliferation rate at each area after 6 days of 194 regeneration was compared to that found in steady-state specimens of H. caerulea (data taken from 195 Alexander et al., 2014) using a linear model. A mixed linear model was used to analyzed the effect of 196 time and area on the proliferation of mesohyl cells, and a linear model was used to determine 197 differences in the percentages of proliferative mesohyl cells at each area during wound healing 198 compared to steady-state $H$. caerulea specimens (data taken from Alexander et al., 2014). All 199 calculations were conducted in R, using the lme4 package for mixed linear models (see S3 for R 200 scripts).

202 Results

All three sponges left to regenerate for six days had completely closed the wound area within

204 this time, leaving no bare substratum exposed (Fig. 1A-D). Six-day old tissue that filled the wound area 205 was slightly different in color compared to fully-developed tissue. A minor depression was left at the 206 surface of the sponge where the wound had been (Fig. 1D). Regenerative wound tissue (Fig. 2A) was 207 void of choanocyte chambers and all cells were BrdU-negative (Fig. 2B). BrdU-positive cells and 208 choanocyte chambers were observed to appear $250 \pm 8.9 \mu \mathrm{m}$ (mean $\pm \mathrm{SE}$ ) from the edge of the wound 209 tissue (Fig. 2A) and were found throughout the rest of the sponge tissue (Fig. 2B). Picrosirius red 210 staining of regenerative wound tissue revealed a high abundance of collagen fibers (a component of the

211 extracellular matrix) compared to areas of tissue away from the wound (Fig. 2C). When viewed using 212 cross polarization filters, picrosirius red staining showed that collagen at and away from the wound 213 area consisted of both thin (green) and thick (orange) fibers (Fig. 2D). Scattered observations were 
made of tracts in the mesohyl close to the site of the wound, which contained BrdU-negative cells (Fig. 2B) and were surrounded by collagen (Fig. 2C).

\section{Choanocyte cell kinetics in early regenerative tissue}

The mouse intestine and sponge positive control tissues showed BrdU-positive nuclei. Negative controls (no primary antibody) and tissue samples at $t=0$ (not labeled with BrdU) showed no BrdUpositive cells. The cell cycle parameters of the choanocyte population directly adjacent to the wound in early regenerative tissue were compared to choanocyte cell kinetics from $H$. caerulea in steady-state (data obtained from De Goeij et al., 2009) (Fig. 3, Table 1). The number of BrdU-positive choanocytes in damaged sponges and steady-state sponges increased linearly until a maximum was reached, after which all proliferative choanocytes had been labeled and had re-entered the S-phase (Fig. 3). This maximum represents the growth fraction, i.e. the percentage of the total population of choanocytes that are proliferative, which was greatly reduced in damaged sponges $(7.0 \pm 2.5 \%)$ compared to steadystate sponges $(46.6 \pm 2.6 \%)$ (Fig. 3, Table 1). However, the cell cycle $\left(\mathrm{T}_{\mathrm{c}}\right)$ of choanocytes adjacent to the wound in damaged sponges was similar in length to the cell cycle of choanocytes from steady-state sponges $(5.6 \pm 3.4 \mathrm{~h}$ vs $5.9 \pm 0.4 \mathrm{~h}$ respectively) (Fig. 3, Table 1).

\section{Cell proliferation during regeneration $(6 \mathrm{~h}-6$ days)}

Oscula in $H$. caerulea were located $1.4 \pm 0.1 \mathrm{~cm}$ from each other. Therefore, tissue samples taken $1 \mathrm{~cm}$ from the wound were likely to be part of the same aquiferous module as the wound, but tissue taken $3 \mathrm{~cm}$ from the wound were likely be from a separate module. Significantly less proliferative choanocytes were found closer to the wound (Fig. 4, Table 2), i.e. less BrdU-positive choanocytes were found directly adjacent to the wound in comparison to $1 \mathrm{~cm}$ from the wound (mixed linear model, $p<0.001$ ) and $1 \mathrm{~cm}$ compared to $3 \mathrm{~cm}$ from the wound (mixed linear model, $p<0.01$ ). 
238 The percentage of proliferative choanocytes increased over time after wound infliction in all tissue 239 areas (Fig. 4): directly adjacent to the wound (linear model, $p<0.01$ ), $1 \mathrm{~cm}$ from the wound (linear 240 model, $p<0.001$ ) and $3 \mathrm{~cm}$ from the wound (linear model, $p<0.01$ ). After six days of regeneration, 241 there was no significant difference between choanocyte proliferation in steady-state $H$. caerulea tissue $242(17.6 \pm 1.9 \%$, data from Alexander et al., 2014) and tissue directly adjacent to the wound $(12.8 \pm 1.0 \%$, 243 linear model, $p=0.19), 1 \mathrm{~cm}$ from the wound $(18.3 \pm 0.4 \%$, linear model, $p=0.99)$ and $3 \mathrm{~cm}$ from the 244 wound (19.1 $\pm 0.5 \%$, linear model, $p=0.94)$ (Fig. 4). On average, there are less BrdU-positive 245 choanocytes directly adjacent to the wound after 6 days of regeneration compared to steady-state tissue 246 (Fig. 4), although not statistically significant.

Between $0.5 \pm 0.2 \%$ and $1.0 \pm 0.4 \%$ of mesohyl cells were proliferative during regeneration.

248 The percentage of proliferative mesohyl cells did not change over time following wound infliction

249 (mixed linear model, $p=0.65$, Table 2) and the percentages of proliferative mesohyl cells from each 250 tissue area (directly adjacent to, $1 \mathrm{~cm}$ and $3 \mathrm{~cm}$ from the wound) were not significantly different to 251 each other (mixed linear model, $p=0.97$ ) or to steady-state tissue (linear model, $p=0.10$ ).

\section{Discussion}

259 Cell kinetics in early regenerative versus steady-state tissue 

to steady-state, undamaged tissue. Directly adjacent to the wound, the choanocyte growth fraction

262 decreased 6.7 fold during initial stages of regeneration. The other cell cycle parameters remained 263 similar in regenerative and steady-state sponges. The reduced growth fraction indicates that fewer cells 264 participate in the proliferation and subsequent turnover of choanocytes adjacent to the wound. The 265 eukaryotic cell cycle has several checkpoints at which intrinsic and extrinsic signals are assessed.

266 Under adverse environmental or physiological conditions, cells can be halted from progression through 267 the cell cycle (Johnson \& Walker 1999; Jonas 2014). The reduced growth fraction of choanocytes 268 adjacent to the wound in early regenerative sponges may be due to choanocytes being halted in their 269 progression through the cell cycle as a result of insufficient energy to progress past the $\mathrm{G}_{1}$ checkpoint. 270 A significant amount of energy is required during cell division for the synthesis of lipids, proteins and 271 nucleic acids (Finkel \& Hwang 2009). Studies on human cancer cell lines (Sweet \& Singh 1995; 272 Gemin et al., 2005, Xiong et al., 2012) and cells of Drosophila larvae (Mandal et al., 2005) show that 273 the $\mathrm{G}_{1}$ checkpoint is energetically sensitive, meaning a minimum ATP content is required to pass the 274 checkpoint and progress through the cell cycle. Measurements of the energetics involved in 275 regeneration for $H$. caerulea are required to confirm this hypothesis. The mesohyl cells are a mixed population of cells including archeocytes, spherulous cells, 277 lophocytes, spongocytes and collencytes (Simpson 1984; Vacelet \& Donadey 1987) and may also 278 include dedifferentiated choanocytes, endopinacocytes and exopinacocytes which have been shown to 279 migrate into the mesohyl during regeneration (Diaz 1979, Simpson 1984). We have found the proliferation of cells located in the mesohyl to be consistently low and does not appear to play a role in 281 early stages of regeneration in H. caerulea. 

and choanocyte turnover (i.e. filter system renewal) are competing and negatively correlated life-

286 history processes. Regeneration takes precedence over choanocyte turnover presumably due to the 287 speed at which it must occur. Rapid regeneration of lost tissue in sponges is necessary to compete for 288 limited space (Jackson \& Palumbi 1979; Turon, Tarjuelo \& Uriz 1998), prevent fouling of exposed 289 spicules (Leys \& Lauzon 1998) and to readjust their size and shape for optimal feeding (Bell 2002). 290 When H. caerulea is damaged, the immediate priority is space occupation of the bare substratum, 291 which may direct energetic resources away from choanocyte proliferation. Following wound infliction, 292 the increase in choanocyte proliferation rates over time indicates that the energy demands of 293 regeneration may decrease over time. The fact that choanocyte proliferation continues, although at a 294 reduced rate, under demanding physiological conditions such as regeneration, highlights the 295 importance of choanocyte turnover in tissue homeostasis to maintain a healthy nutrient uptake system 296 (De Goeij et al., 2009; Alexander et al., 2014). Rapid choanocyte turnover has been documented in 297 multiple sponge species from tropical reef, mangrove and temperate ecosystems (Alexander et al., 298 2014). However, sponges vary widely in their ability to regenerate and recover from injury depending 299 300 301 on their morphology, structural complexity, susceptibility to damage, and chemical defenses (Wulff 2006a; Walters \& Pawlik 2005; Wulff 2010). Therefore, the relationship between regeneration and choanocyte renewal may vary depending on the species.

After six days of regeneration, choanocyte proliferation rates in regenerative sponges were comparable to that of steady-state, undamaged sponges $(17.6 \pm 1.9 \%)$ measured in the same runningseawater aquaria during the same field work campaign as the sponges used in the current study

305 (Alexander et al., 2014). However, these proliferation rates are substantially lower than rates measured 306 from sponges kept in the same aquaria in 2009 (46.6 $\pm 2.6 \%$; De Goeij et al., 2009). Our results 307 corroborate the suggestion that the lower proliferation rates measured in steady-state sponges by 
308 Alexander and colleagues (2014) result from a reduced growth fraction rather than a change in the 309 length of the cell cycle. We hypothesize that suboptimal nutritional conditions are the cause of these 310 differences (Alexander et al., 2014) and this relationship needs to be analyzed further. Nutrition plays 311 an important role in wound healing in humans (reviewed by Reynolds 2001) and the allocation of 312 energy to limb regeneration has been found to depend on levels of available food in the asteroid Luidia 313 clathrata (Lawrence et al., 1986; Lawrence \& Elwood 1991). Low food availability can exaggerate 314 energy trade-offs in insects (reviewed by Zera \& Harshman 2001), and therefore under optimal 315 nutritional conditions the trade-off between regeneration and choanocyte proliferation in $\mathrm{H}$. caerulea 316 may not be as evident.

Regeneration is a common phenomenon occurring in many metazoan tissues, however, the 318 extent to which tissues can regenerate to a fully functional state and the cellular mechanisms involved in regeneration vary widely (reviewed by Tanaka \& Reddien 2011). In many cases, the proliferation of stem cells increases during regeneration. Highly proliferative tissues often maintain a pool of quiescent stem cells that divide in response to injury e.g. in mammalian intestinal stem cells (Buczacki et al., 323 resulting from mid-gastric amputation (Govindasamy, Murthy \& Ghanekar 2014). Regeneration can 324 also occur through the rearrangement of pre-existing tissue in the absence of cell proliferation, e.g. in 325 head regeneration following decapitation in Hydra (Holstein, Hobmayer \& David 1991; Bosch 2007).

326 Regeneration in sponges has generally been shown to be a result of remodeling and reorganization of 327 pre-exisiting tissue involving both collagen production and the migration if cells to the wound in 328 mesohyl tracts (e.g. Harrison 1972; Boury-Esnault 1976; Jackson \& Palumbi 1979; Simpson 1984;

329 Smith \& Hildemann 1986; Louden et al., 2007). We have shown that regeneration in H. caerulea does 330 not involve an increase in cell proliferation. Although the cellular mechanisms responsible for the 
331 production of early regenerative tissue in $H$. caerulea remain unknown, collagen production and 332 mesohyl tracts are likely to play a role.

333

334 Organismal integration during regeneration

The degree of integration between aquiferous modules during regeneration in sponges is

unclear, with some evidence suggesting that resources required for regeneration are derived from tissue

337 in the immediate vicinity of the wound (Boury-Esnault 1976; Wulff 1991). Others suggest that

338 resources may be contributed from a more extensive distance from the wound (Boury-Esnault \&

339 Doumenc 1978; Wulff 2006b; Henry \& Hart 2005), as occurs in other modular organisms such as

340 corals (Oren, Rinkevich \& Loya 1997; Oren et al., 2001). Integration between modules during

341 regeneration in sponges may be dependent on the size of the wound. In the coral Favia favus, the

342 regeneration of small wounds $\left(<1 \mathrm{~cm}^{2}\right)$ demands only localized resources while regeneration of larger

343 wounds involves an integrated response of the organism (Oren et al., 2001). We have shown that

344 during the regeneration of small wounds in H. caerulea, the proliferation of choanocytes located

345 farther from the wound were less affected by the process of regeneration. This suggests that the

346 regeneration of small wounds demands resources mainly from tissue in their immediate vicinity. Since

347 choanocyte proliferation rates are reduced during initial stages of regeneration, even at a distance of 3

$348 \mathrm{~cm}$ from the wound, we conclude that some degree of integration between modules occurs. In order to

349 measure the full extent of organismal integration, the effect of regeneration on choanocyte proliferation

350 should be determined using larger specimens of $H$. caerulea, which we have observed growing in situ

351 up to meters in size, and using larger wounds. The organization of sponge tissue into repeated

352 functional units (modules) allows multioscular sponges to function and survive if separated into

353 smaller pieces due to fragmentation (Ereskovskii 2003). However, the ability to provide an integrated 
354 physiological response during periods of stress is an important survival strategy for modular organisms 355 (Oren et al., 2001).

\section{Conclusions}

358 This study demonstrates the inhibitory effect of regeneration on cell proliferation in $H$.

359 caerulea, and the gradual return over time to proliferation rates found in steady-state, undamaged

360 tissue. We provide evidence for a trade-off between choanocyte proliferation and regeneration.

361 Furthermore, these results demonstrate that the impact of regeneration on cell proliferation decreases

362 farther from the wound, indicating that the wound demands more resources from tissue in its

363 immediate vicinity. An understanding of the relationship between regeneration and choanocyte

364 renewal, two life-history traits essential to the survival of sponges, allows us to gain insight into the

365 physiological functioning responsible for the ecological success of one of the first extant multicellular 366 organisms on Earth. 


\section{Acknowledgements}

370

371

372

373

374

375

376

377 References 121.
We thank Fabiènne Doveren and Kevin Liebrand for their assistance in the field and lab; staff at the CARMABI institute for their hospitality during field work; Henk van Veen, Wikky Tigchelaar and the staff of the electron microscopy lab at the Academic Medical Center (AMC) Amsterdam for their support in histology; the Earth Surface Sciences Department at the Institute for Biodiversity and Ecosystem Dynamics (ESS-IBED), University of Amsterdam for access to their microscopy facilities;

Emiel van Loon for advice on statistical analyses and Henk Kieft for help with BMM embedding.

1. Aldewachi H, Wright N, Appleton D, Watson A. 1975. Effect of starvation and refeeding on cell-population kinetics in rat small bowel mucosa. Journal of Anatomy 119: 105-

2. Alexander BE, Liebrand K, Osinga R, van der Geest HG, Admiraal W, Cleutjens JPM, Schutte B, Verheyen F, Ribes M, van Loon E, de Goeij JM. 2014. Cell turnover and detritus production in marine sponges from tropical and temperate benthic ecosystems. PLoS ONE 9(10): e109486.

3. Antcliffe JB, Callow RHT, Brasier MD. 2014. Giving the early fossil record of sponges a squeeze. Biological Reviews 89: 972-1004.

4. Ayling AL.1983. Growth and regeneration rates in thinly encrusting demospongiae from temperate waters. Biological Bulletin 165: 343-352.

5. Bell JJ, Barnes DKA. 2000. A sponge diversity centre within a marine 'island'. Hydrobiologia 440: 55-64. 
390

391

392

393

394

395

396

397

398

399

400

401

402

403

404

405

406

407

408

409

410

411

412

6. Bell JJ, Barnes DKA, Turner JR. 2002. The importance of micro and macro morphological variation in the adaptation of a sublittoral demosponge to current extremes. Marine Biology 140: $75-81$.

7. Bell JJ. 2002. Regeneration rates of a sublittoral demosponge. Journal of the Marine Biology Association UK 82: 169-170.

8. Bosch TC. 2007. Why polyps regenerate and we don't: towards a cellular and molecular framework for Hydra regeneration. Developmental Biology 303: 421-433.

9. Boshuizen JA, Reimerink JH, Korteland-van Male AM, van Ham VJ, Koopmans MP, Büller HA, Dekker J, Einerhand AW. 2003. Changes in small intestinal homeostasis, morphology, and gene expression during rotavirus infection of infant mice. Journal of Virology 77: 1300513016.

10. Boury-Esnault N. 1976. Morphogenese experimentale des papilles inhalanted de l'eponge Polymastia mamillaris (Müller). Archives de Zoologie Expérimentale et Générale 117: 181196.

11. Boury-Esnault N, Doumenc DA. 1978. Glycogen storage and transfer in primitive invertebrates: demospongea and actiniaria. Colloques Internationaux du Centre National de la Recherche Scientifique 291: 181-192.

12. Buchon N, Broderick NA, Poidevin M, Pradervand S, Lemaitre B. 2009. Drosophila intestinal response to bacterial infection: activation of host defense and stem cell proliferation. Cell Host Microbe 5: 200-211.

13. Buczacki SJA, Zecchini HI, Nicholson AM, Russell R, Vermeulen L, Kemp R, Winton DJ. 2013. Intestinal label-retaining cells are secretory precursors expressing Lgr5. Nature 495: 6569. 
14. Chaudhary M, Mandir N, FitzGerald AJ, Howard JK, Lord GM, Ghatei MA, Bloom SR, Goodlad RA. 2000. Starvation, leptin and epithelial cell proliferation in the gastrointestinal tract of the mouse. Digestion 61: 223-229.

15. De Goeij JM, De Kluijver A, Van Duyl FC, Vacelet J, Wijffels RH, De Goeij AF, Cleutjens JP, Schutte B. 2009. Cell kinetics of the marine sponge Halisarca caerulea reveal rapid cell turnover and shedding. The Journal of Experimental Biology 212: 3892-3900.

16. De Goeij JM, Van Oevelen D, Vermeij MJA, Osinga R, Middelburg JJ, De Goeij AFPM, Admiraal W. 2013. Surviving in a marine desert: the sponge loop retains resources within coral reefs. Science 342: $108-110$.

17. Diaz JP. 1979. Variations, differenciations et fonctions des categories cellulaire de la demosponge d'eau saumaitres, Suberites massa Nardo, au cours du cycle biologique annuel et dans des conditions experimentales. Thesis, University Science and Technology Languedoc.

18. Ereskovskii AV. 2003. Problems of coloniality, modularity, and individuality in sponges and special features of their morphogenesis during growth and asexual reproduction. Russian Journal of Marine Biology 29: S46-S56.

19. Finkel T, Hwang PM. 2009. The krebs cycle meets the cell cycle: mitochondria and the $\mathrm{G}_{1}-\mathrm{S}$ transition. Proceedings of the National Academy of Sciences of the United States of America 106: $11825-11826$.

20. Fry WG. 1970. The sponge as a population: a biometric approach. Symposia of the Zoological Society of London 25: 135-162.

21. Fry WG. 1979. Taxonomy, the individual and the sponge. In: Biology and Systematics of colonial organisms. London; New York: Academic Press, 39-47. 
435

436

437

438

439

440

441

442

443

444

445

446

447

448

449

450

451

452

453

454

455

456

457

458

22. Funayama N. 2013. The stem cell system in demosponges: suggested involvement of two types of cells: archeocytes (active stem cells) and choanocytes (food-entrapping flagellated cells). Development Genes and Evolution 223: 23-38.

23. Gemin A, Sweet S, Preston TJ, Singh G. 2005. Regulation of the cell cycle in response to inhibition of mitochondrial generated energy. Biochemical and Biophysical Research Communications 332: 1122-1132.

24. Gaino E, Burlando B. 1990. Sponge cell motility: a model system for the study of morphogenic processes. Bolletino di Zoologia 57: 109-118.

25. Gaino E, Manconi R, Pronzato, R. 1995. Organizational plasticity as a successful conservative tactic in sponges. Animal Biology 4: 31-43.

26. Gilbert S, Nivarthi H, Mayhew CN, Lo Y-H, Noah TK, Vallance J, Rülicke T, Müller M, Jegga AG, Tang W, Zhang D, Helmrath M, Shroyer N, Moriggl R, Han X. 2015. Acitvated STAT5 confers resistance to intestinal injury by increasing intestinal stem cell proliferation and regeneration. Stem Cell Reports 4: 1-17.

27. Gili J-M, Coma, R. 1998. Benthic suspension feeders: their paramount role in littoral marine food webs. Trends in Ecology and Evolution 13: 316-321.

28. Govindasamy N, Murthy S, Ghanekar, Y. 2014. Slow-cycling stem cells in hydra contribute to head regeneration. Biology Open 000: 1-9.

29. Harrison FW. 1972. The nature and role of the basal pinacoderm of Corvomeyenia carolinensis (Porifera: Spongillidae). Hydrobiologia 39: 495-508.

30. Henry LA, Hart M. 2005. Regeneration from injury and resource allocation in sponges and corals - a review. International Review of Hydrobiology 90: 125-158.

31. Holstein TW, Hobmayer E, David CN. 1991. Pattern of epithelial cell cycling in hydra. Developmental Biology 148: 602-611. 
459

460

461

462

463

464

465

466

467

468

469

470

471

472

473

474

475

476

477

478

479

480

481

32. Jackson JBC, Palumbi SR. 1979. Regeneration and partial predation in cryptic coral reef environments: preliminary experiments on sponges and ectoprocts. In: Levi C, Boury-Esnault N ed. Biologie des spongiaires. Paris: Colloques Interationaux du CNRS, 303-308.

33. Jiang H, Grenley MO, Bravo M, Blumhagen RZ, Edgar BA. 2011. EGFR/Ras/MAPK signaling mediates adult midgut epithelial homeostasis and regeneration in Drosophila. Cell Stem Cell 8: 84-95.

34. Johnson DG, Walker CL. 1999. Cyclins and cell cycle checkpoints. Annual Review of Pharmacology and Toxicology 39: 295-312.

35. Jonas K. 2014. To divide or not to divide: control of the bacterial cell cycle by environmental cues. Current Opinion in Microbiology 18: 54-60.

36. Junqueira LCU, Montes GS, Sanchez EM. 1982. The influence of tissue section thickness of the study of collagen by the picrosirius-polarization method. Histochemistry 74: 153-156.

37. Koopmans M, van Rijswijk P, Martens D, Egorova-Zachernyuk TA, Middelburg JJ, Wijffels RH. 2011. Carbon conversion and metabolic rate in two marine sponges. Marine Biology 158: $9-20$.

38. Lawrence JM, Klinger JB, McClintock SA, Watts CP, Chen A, Smith L. 1986. Allocation of nutrient resources to body compartments by regenerating Luidia clathrata (Say) (Echinodermata: Asteroidea). Journal of Experimental Marine Biology and Ecology 102: 4753.

39. Lawrence JM, Ellwood A. 1991. Simultaneous allocation of resources to arm regeneration and to somatic and gonadal production in Luidia clathrata (Say) (Echinodermata: Asteroidea) In: Yanagisawa T, Yasumasu I, Oguro C, Suzuki N, Motokawa T, ed. Biology of Echinodermata. Rotterdam: Balkema 543-548. 
40. Leong W, Pawlik JR. 2010. Evidence of a resource trade-off between growth and chemical defenses among Caribbean coral reef sponges. Marine Ecology Progress Series 406: 71-78.

41. Leys SP, Lauzon NRJ. 1998. Hexactinellid sponge ecology: growth rates and seasonality in deep water sponges. Journal of Experimental Marine Biology and Ecology 230: 111-129.

42. Li L, Clevers H. 2010. Coexistence of quiescent and active adult stem cells in mammals. Science 327: 542-545.

43. Luter HM, Whalen S, Webster NS. 2012. The marine sponge Ianthella basta can recover from stress-induced tissue regression. Hydrobiologa 687: 227-235.

44. Louden D, Whalen S, Evans-Illidge E, Wolff C, de Nys R. 2007. An assessment of the aquaculture potential of the tropical sponges Rhopaloeides odorabile and Coscinoderma sp. Aquaculture 270: 57-67.

45. Mandal S, Guptan P, Owusu-Ansah E, Banerjee U. 2005. Mitochondrial regulation of cell cycle progression during development as revealed by the tenured mutation in Drosophila. Developmental Cell 9: 843-854.

46. McLeod CJ, Wang L, Wong C, Jones DL. 2010. Stem cell dynamics in response to nutrient availability. Current Biology 20: 2100-2105.

47. McClintock J, Amsler CD, Baker BJ, van Soest RWM. 2005. Ecology of Antarctic marine sponges: an overview. Integrative and Comparative Biology 45: 359-368.

48. Müller WEG. 1998. Origin of metazoan: sponges as living fossils. Naturwissenschaften 85: 11-25.

49. Müller WEG. 2006. The stem cell concept in sponges (Porifera): metazoan traits. Seminars in Cell and Developmental Biology 17: 481-491.

50. Nowakowski RS, Lewin SB, Miller MW. 1989. Bromodeoxyuridine immunohistochemical determination of the lengths of the cell cycle and the DNA-synthetic phase for an anatomically defined population. Journal of Neurocytology 18: 311-318. 
506

507

508

509

510

511

512

513

514

515

516

517

518

519

520

521

522

523

524

525

526

527

528

51. Oren U, Rinkevich B, Loya Y. 1997. Oriented intra-colonial transport of 14C labeled materials during regeneration in scleractinian corals. Marine Ecology Progress Series 161: 117-121.

52. Oren U, Benayahu Y, Lubinevsky H, Loya Y. 2001. Colony integration during regeneration in the stony coral Favia favus. Ecology 82: 802-813.

53. Philippe H, Derelle R, Lopez P, Pick K, Borchiellini C, Boury-Esnault N, Vacelet J, Renard E, Houliston E, Quéinnec E, Da Silva C, Wincker P, Le Guyader H, Leys S, Jackson DJ, Schreiber F, Erpenbeck D, Morgenstern B, Wörheide G, Manuel M. 2009. Phylogenomics revives traditional views on deep animal relationships. Current Biology 19:706-712.

54. Reynolds TM. 2001. The future of nutrition and wound healing. Journal of Tissue Viability 11: 5-13.

55. Simpson TL. 1984. The cell biology of sponges. New York: Springer-Verlag.

56. Smith LC, Hildemann WH. 1986. Allograft rejection, autograft fusion and inflammatory responses to injury in Callyspongia diffusa (Porifera; Demospongia). Proceedings of the Royal Society London 226: 445-464.

57. Sweet S, Singh G. 1995. Accumulation of human promyelocytic leukemic (HL-60) cells at two energetic cell cycle checkpoints. Cancer Research 55: 5164-5167.

58. Tanaka EM, Reddien PW. 2011.The cellular basis for animal regeneration. Developmental Cell 21: $172-185$.

59. Turon X, Tarjuelo I, Uriz MJ. 1998. Growth dynamics and mortality of the encrusting sponge Crambe crambe (Poecilosclerida) in contrasting habitats: correlation with population structure and investment in defence. Functional Ecology 12: 631-639.

60. Vacelet J, Donadey C. 1987. A new species of Halisarca (Porifera: Demospongiae) from the Caribbean, with remarks on the cytology and affinities of the genus. In: Jones WC, ed. 
European contribution to the taxonomy of sponges. Sherkin Island Marine Station Publications, 5-12.

61. Van Soest RWM, Boury-Esnault N, Hooper JNA, Rützler K, de Voogd NJ, Alvarez de Glasby B, Hajdu E, Pisera AB, Manconi R, Schoenberg C, Janussen D, Tabachnick KR, Klautau M, Picton B, Kelly M, Vacelet J, Dohrmann M, Díaz MC, Cárdenas P. 2015. World porifera database. Available at http://www.marinespecies.org/porifera (accessed 2 February 2015).

62. Walters KD, Pawlik JR. 2005. Is there a trade-off between wound-healing and chemical defences among Caribbean reef sponges? Integrative and Comparative Biology 45: 352-358. 63. Wulff JL. 1991. Asexual fragmentation, genotype success, and population dynamics of erect branching sponges. Journal of Experimental Marine Biology and Ecology 149: 227-247.

64. Wulff JL. 2006a. Resistance vs recovery: morphological strategies of coral reef sponges. Functional Ecology 20: 699-708.

65. Wulff JL. 2006b. A simple model of growth form-dependent recovery from disease in coral reef sponges, and implications for monitoring. Coral Reefs 25: 419-426.

66. Wulff J. 2010. Regeneration of sponges in ecological context: is regeneration an integral part of life history and morphological strategies? Integrative and Comparative Biology 50: 494-505.

67. Xiong W, Jiao Y, Huang W, Ma M, Yu M, Cui Q, Tan D. 2012. Regulation of the cell cycle via mitochondrial gene expression and energy metabolism in HeLa cells. Acta Biochemica et Biophysica Sinica 44: 347-358.

68. Zera AJ, Harshman, LG. 2001. The physiology of life history trade-offs in animals. Annual Review of Ecological Systems 32: 95-126. 
Table $\mathbf{1}$ (on next page)

Estimated cell cycle parameters (mean $\pm 95 \%$ confidence intervals) of choanocytes in steady-state and early regenerative tissue of $H$. caerulea

Steady-state data obtained from De Goeij and colleagues (2009). The growth fraction (GF) represents the percentage of proliferative choanocytes. $T_{c}$ is the lengthof the cell cycle, $T_{s}$ is the length of the S-phase, and the labeling index (LI) represents the percentage of choanocytes in S-phase. 


\begin{tabular}{ccc}
\hline & Steady-state & Early Regenerative \\
\hline GF (\%) & $46.6 \pm 2.6$ & $7.0 \pm 2.5$ \\
$\mathrm{~T}_{\mathrm{c}}(\mathrm{h})$ & $5.9 \pm 0.4$ & $5.6 \pm 3.4$ \\
$\mathrm{~T}_{\mathrm{S}}(\mathrm{h})$ & $0.5 \pm 0.3$ & $0.9 \pm 2.5$ \\
$\mathrm{LI}(\%)$ & $3.9 \pm 1.2$ & $1.1 \pm 1.1$ \\
\hline
\end{tabular}

3

4 


\section{Table 2 (on next page)}

Cell proliferation during regeneration in $\mathrm{H}$. caerulea

Percentages ( \pm SE) of proliferative choanocytes (Ch) and mesohyl cells $(\mathrm{Me})$ in different tissue areas of $H$. caerulea during regeneration. 


\begin{tabular}{rcccccc}
\hline & \multicolumn{2}{c}{ Adjacent to wound } & \multicolumn{2}{c}{$1 \mathrm{~cm}$ from wound } & \multicolumn{2}{c}{$3 \mathrm{~cm}$ from wound } \\
\hline & \multicolumn{1}{c}{$\% \mathrm{Ch}$} & \multicolumn{1}{c}{$\% \mathrm{Me}$} & \multicolumn{1}{c}{$\% \mathrm{Ch}$} & \multicolumn{1}{c}{$\% \mathrm{Me}$} & \multicolumn{1}{c}{$\% \mathrm{Ch}$} & $\% \mathrm{Me}$ \\
\hline 6h & $6.9 \pm 0.6$ & $0.7 \pm 0.3$ & $8.4 \pm 0.8$ & $0.6 \pm 0.8$ & $12.5 \pm 0.3$ & $1.0 \pm 0.4$ \\
1d & $7.4 \pm 0.8$ & $0.9 \pm 0.6$ & $12.1 \pm 1.3$ & $0.8 \pm 0.3$ & $15.3 \pm 0.9$ & $0.9 \pm 0.3$ \\
2d & $11.9 \pm 0.9$ & $0.8 \pm 0.3$ & $13.1 \pm 0.5$ & $0.8 \pm 0.4$ & $15.4 \pm 0.5$ & $0.6 \pm 0.3$ \\
6d & $12.8 \pm 1.0$ & $0.7 \pm 0.2$ & $18.3 \pm 0.4$ & $0.9 \pm 0.3$ & $19.1 \pm 0.5$ & $0.5 \pm 0.2$ \\
\hline
\end{tabular}

3 


\section{1}

Regeneration in $H$. caerulea (A) directly, (B) one day, (C) two days, and (D) six days after wound infliction

After six days, sponges had completely filled in the bare substrate exposed by the initial wound with a thin layer of regenerative wound tissue. Tissue samples were taken directly adjacent to the wound, $1 \mathrm{~cm}$ from the wound and $3 \mathrm{~cm}$ from the wound (A). Tissue samples taken adjacent to the wound were marked with an arrow shape so that the orientation of the tissue could be recognized and histological sections could be made which included the wound area (A). Within each tissue sample three histological sections were analyzed, each $100 \mu \mathrm{m}$ apart, represented by the solid black lines (A). 


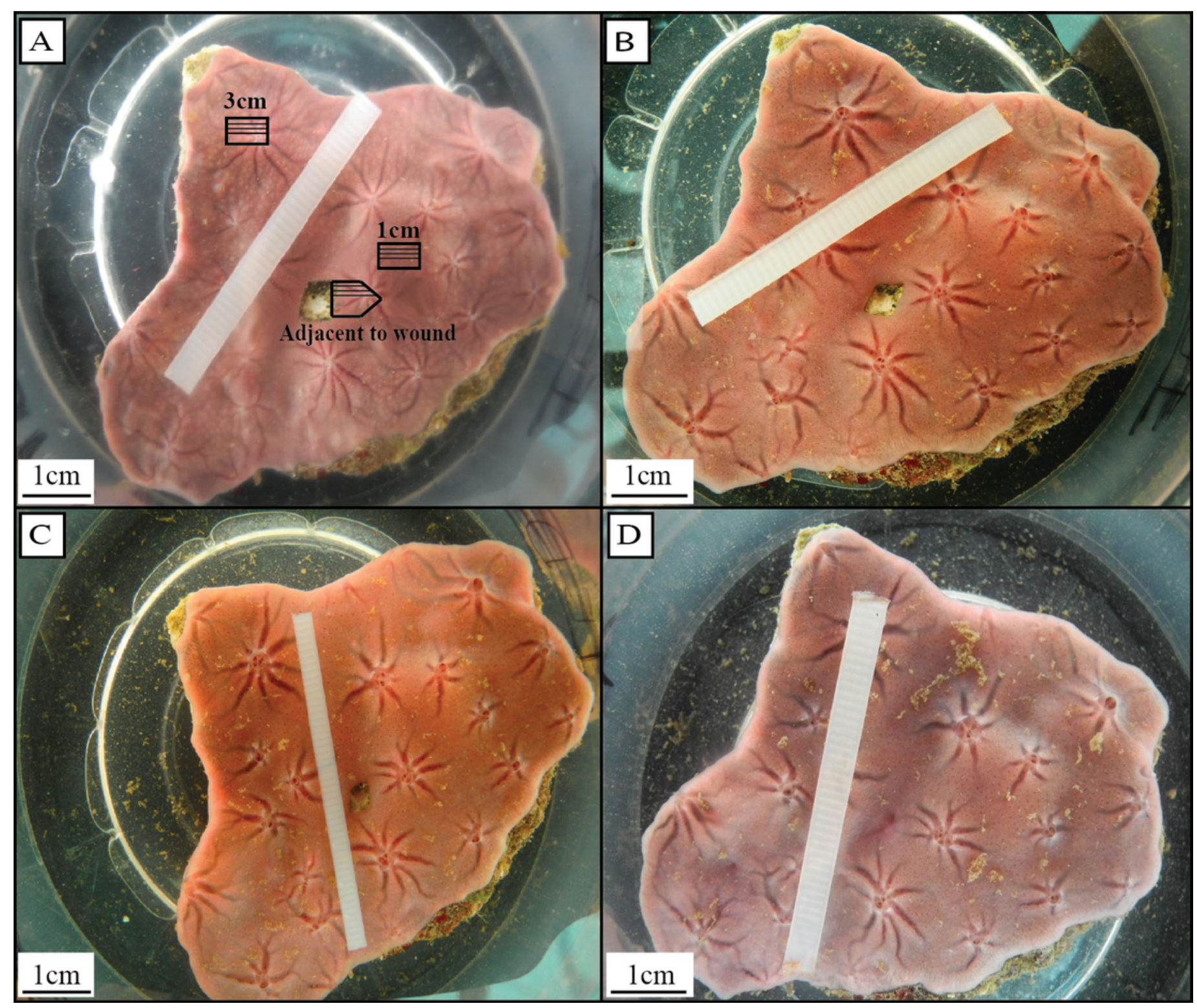




\section{2}

Regenerative tissue of $H$. caerulea

(A) Cross-section through BrdU and hematoxylin stained sponge tissue two days after wound infliction, showing regenerative tissue at the site of the wound, the location of mesohyl tracts containing cells, which were occasionally observed close to the wound, and an area away from the wound containing choanocyte chambers. Choanocyte chambers appeared $250 \pm 8.9$ $\mu \mathrm{m}$ from the edge of the wound tissue. (B) BrdU immunohistochemistry of a regenerative sponge labeled with BrdU for $6 \mathrm{~h}$. Brdu-positive cells (brown-stained nuclei) were absent from regenerative wound tissue, and cells located in mesohyl tracts were BrdU-negative (bluestained nuclei, white arrows). Tissue areas away from the wound that had retained their structural integrity contained BrdU-positive choanocytes (black arrows) and occasionally BrdU-positive mesohyl cells (black arrow heads). (C) Picrosirius red staining showed a higher density of collagen in regenerative wound tissue compared to areas farther from the wound. High densities of collagen could also be seen surrounding tracts in the mesohyl containing cells (white arrows). (D) Visualization of picrosirius red staining under cross polarized light revealed thin (green) and thick (orange) collagen fibers in all tissue areas. 

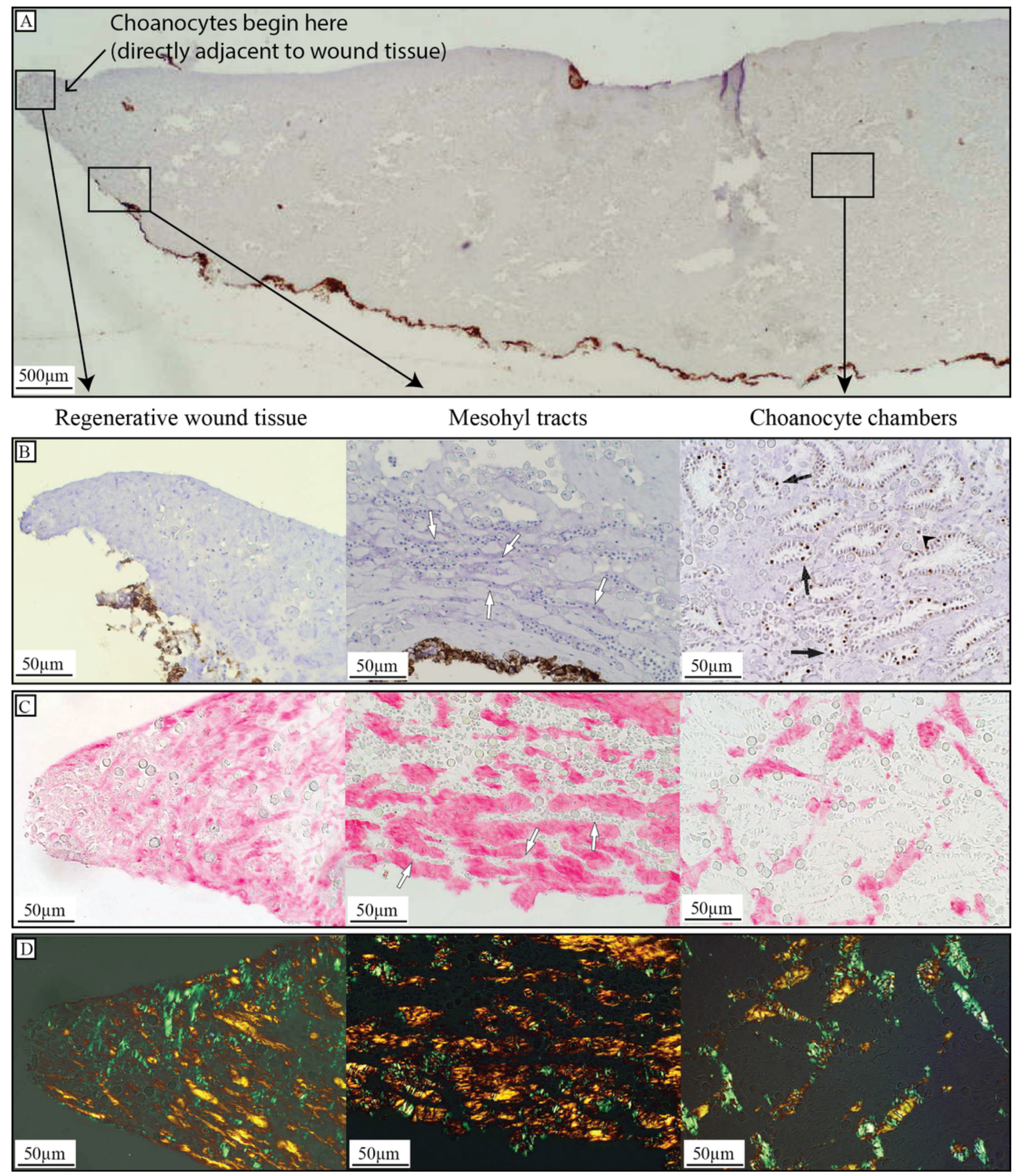


\section{3}

Choanocyte cell kinetics in early regenerative and steady-state tissue of $H$. caerulea

Steady-state data were obtained from De Goeij and colleagues (2009). In both tissues, the percentage of BrdU-positive choanocytes (mean $\pm \mathrm{SE}$ ) increased over time until a maximum was reached, representing the growth fraction (GF) i.e. the percentage of choanocytes involved in proliferation. The growth fraction of choanocytes in early regenerative tissue was substantially lower than the growth fraction of choanocytes from steady-state tissue. The duration of the linear increase represents the length of the cell cycle, which was similar in regenerative and steady-state sponges. The lines are the least squares fit obtained using the conditions of the 'one population model' described by Nowakowski and colleagues (1989).

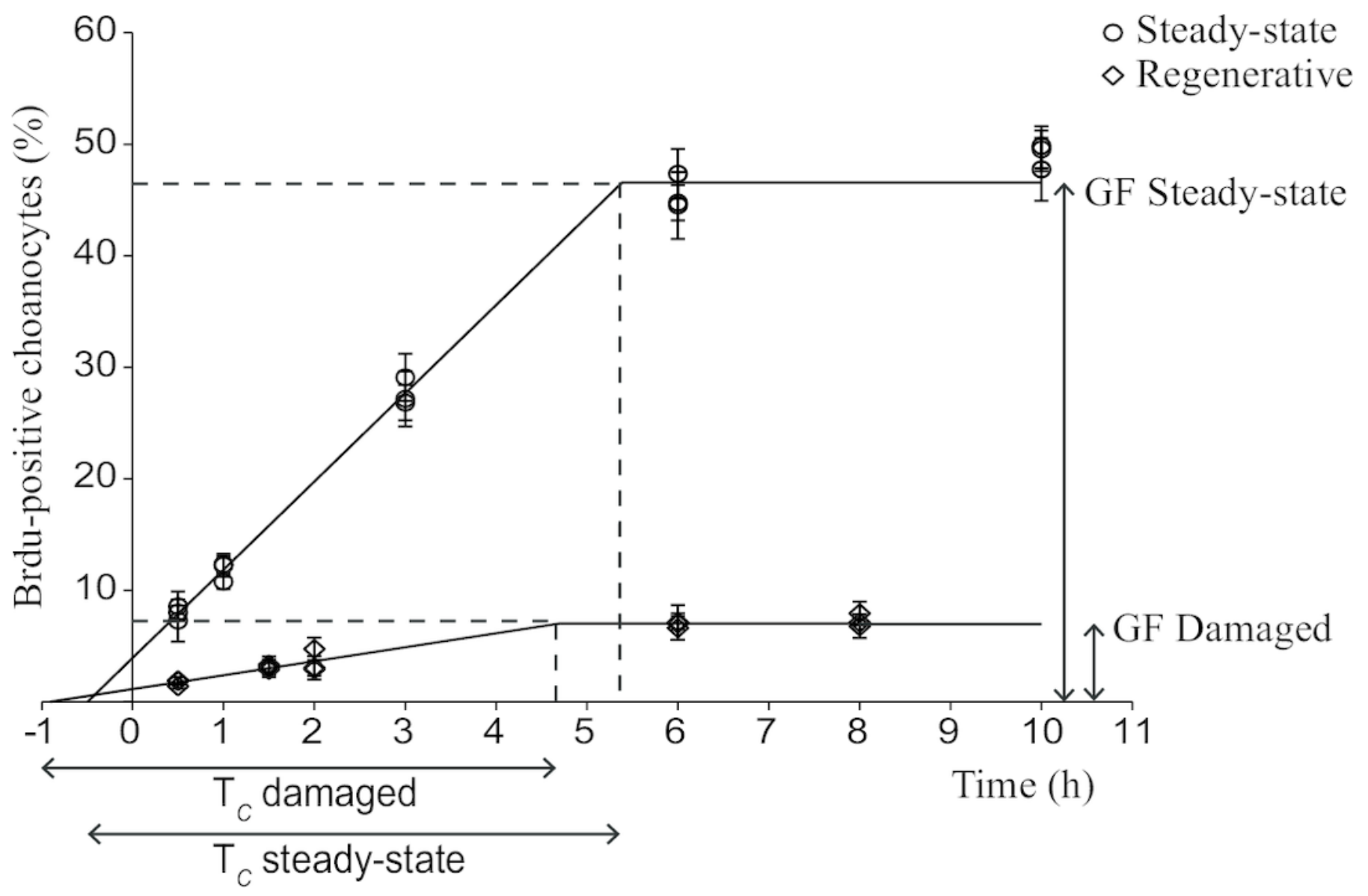




\section{4}

Changes in choanocyte proliferation rates over time in $\mathrm{H}$. caerulea during regeneration There are significantly less proliferative choanocytes closer to the wound compared to $1 \mathrm{~cm}$ and $3 \mathrm{~cm}$ from the wound (mean $\pm \mathrm{SE}$ ). The percentage of proliferative choanocytes increases over time in each tissue area. The percentage of proliferative choanocytes six days after damage, in tissue located $1 \mathrm{~cm}$ and $3 \mathrm{~cm}$ from the wound, are comparable to the percentage of proliferative choanocytes found in steady-state $\mathrm{H}$. caerulea specimens (data taken from Alexander and colleagues (2014); grey area depicts mean \pm SE).

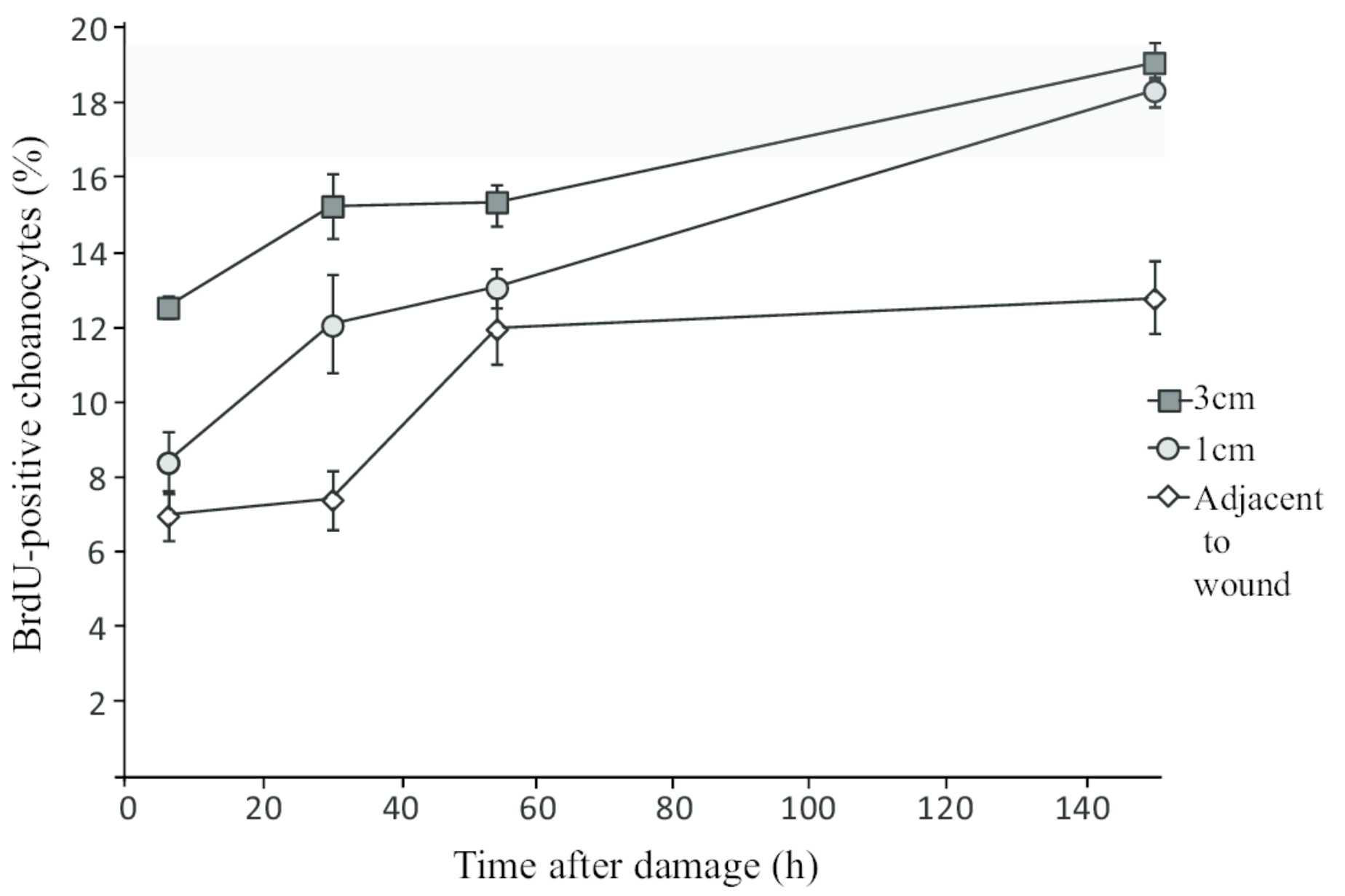

